\title{
Liver transplantation as a lifesaving procedure for posthepatectomy liver failure and iatrogenic liver injuries
}

\author{
Trygve Thorsen ${ }^{1,2}$ \& Jon Magnus Solheim ${ }^{1,2}$ \& Knut Jørgen Labori ${ }^{3}$ \& Pål-Dag Line ${ }^{1,2}$ \& Einar Martin Aandahl ${ }^{1,4}$
}

\begin{abstract}
Background Iatrogenic injuries to vital structures of the liver and posthepatectomy liver failure are associated with high mortality.

The current donor situation in Norway allows liver transplantation of patients beyond conventional criteria.

Methods From 1984 to 2017, a total of 1510 liver transplantations were performed. In this retrospective study, we report the results of 13 patients undergoing liver transplantation due to iatrogenic injuries to the liver vasculature or posthepatectomy liver failure.

Results Twelve men and one woman with a median age of 55 years (range 22-69) were included. Seven patients underwent radical surgery for cancer prior to transplantation. The median follow-up time was 70.5 months (range 2.2177). Three of the patients with malignant disease did not experience disease recurrence, whereas four patients had cancer recurrence and died 7, 24, 45, and 78 months after transplantation. Five of six patients with non-malignant disease fully recovered, but one patient died after 9 months due to infectious complications.

Conclusions Liver transplantation for liver failure due to portal vein and hepatic artery injury in patients with nonmalignant disease seems justified. However, it may be questioned whether patients with malignant disease beyond established criteria should be offered liver transplantation.
\end{abstract}

Keywords Liver transplantation ${ }^{\circ}$ Rescue ${ }^{`}$ Iatrogenic injuries ${ }^{`}$ Posthepatectomy liver failure

\section{Introduction}

Liver transplantation (LT) is the only curative treatment for a wide range of diseases resulting in end-stage liver disease. LT is also offered to patients with hepatocellular carcinoma (HCC) within established criteria for disease stage. However, few studies have evaluated urgent rescue LT as a lifesaving treatment for patients suffering from acute liver failure (ALF) after liver resection or severe injuries to vital structures of the liver. Previous studies have mainly examined

* Trygve Thorsen

thorsen_t@yahoo.no; thorsen@ous-hf.no

1 Section for Transplant Surgery, Oslo University Hospital Rikshospitalet, Sognsvannsveien 20, 0372 Oslo, Norway

2 Institute for Clinical Medicine, University of Oslo, Oslo, Norway

3 Department of Hepato-Pancreato-Biliary Surgery, Oslo University Hospital Rikshospitalet, Oslo, Norway

4 Institute for Cancer Research, Oslo University Hospital, Oslo, Norway
LT after fatal bile duct injuries acquired during cholecystecto-my [1-8], while other indications such as iatrogenic injuries to the portal vein during bariatric surgery [9], bleeding-complications related to insertion of transjugular intrahepatic portosystemic shunt [10], and ALF after coiling of the hepatic artery [11] have been reported in smaller case series or single cases. Emergent LT as treatment after fatal injuries to the por-tal vein and hepatic artery during open adrenalectomy [4, 12], and LT as a bailout solution after uncontrollable bleeding in relation to resection surgery $[11,13]$ have also been described.

The donation rates in Norway have varied between 20.4 and 21.8 per million of the population during the last 5 years and the wait list mortality has been below $3 \%$. Our hospital is the only transplant center in Norway, and performs around 100 LTs per year. The current situation with short waiting list and good access to organs has allowed us to explore expanded indications for LT, giving rise to the SECA-study [14-16], the RAPID concept [17] and extended criteria for LT in patients with HCC beyond those established internationally [18]. The aim of the study was to report our institutional experience with rescue LT in patients suffering from ALF due to injuries to the portal vein and hepatic artery or following liver resection. 
Between 1984 and 2017, 1510 LTs were performed in our institution. Thirteen LTs were done as urgent procedures due to iatrogenic injuries of vital hepatic vasculature or ALF after prior liver resections. Complete medical files of all patients were available for data-extraction. Data on the corresponding donors were collected from our local registry. The study was approved by the institutional review board according to the general guidelines provided by the regional ethics committee (2015/1442).

All patients received standard triple immunosuppression (IS) with tacrolimus in combination with steroids and mycophenolate mofetil, and except patient no. 12 all received induction therapy with anti-IL-2 receptor antibody (basiliximab) with delayed introduction of tacrolimus due to kidney dysfunction at the time of transplantation. Due to ABO-incompatibility, patient no. 10 received $45 \mathrm{~g}$ intravenous immunoglobulins for 4 days and a single dose of $850 \mathrm{mg}$ anti-CD20 antibody (rituximab) in addition to standard IS. Due to changes in our IS-protocol during the study period, patient no. 4 and 11 did not receive IVIG/rituximab despite ABO-incompatible LT. All operations were performed using piggy-back technique without use of veno-venous bypass, and only full liver grafts were used. The severity of liver failure was categorized according to MELD score [19].

\section{Results}

Twelve men and one woman were included in the study. The median age was 55 years (range 22-69). Patient characteristics, indications for liver transplantation and main outcome are presented in Table 1. Six patients (cases 1-6, Table 1) were transplanted due to complications after surgical procedures for non-malignant tumors or conditions.

Seven patients (cases 7-13, Table 1) had undergone radical surgery for various malignancies prior to transplantation.

Perioperative data are presented in Table 2. Median time from the primary procedure until LT was 17 days (range 037), and the median waiting-time after the patient was listed for LT was one day (range 0-7). Median MELD score was 33.5 (range 22-40). The median donor age was 56 years (range 18-83). Median cold ischemia time (CIT) was $423 \mathrm{~min}$ (range 210-642). The median intraoperative blood transfusion was $3000 \mathrm{ml}$ (range 250-27,250).

There were three incidents of primary non-function (PNF) or dysfunction requiring early retransplantation after the rescue procedure. All these were related to marginal liver graft quality with no signs of technical issues as the cause of PNF. Two of the primary LTs $(\mathrm{A} \rightarrow 0)$ and one retransplantation $(\mathrm{AB} \rightarrow \mathrm{A})$ were $\mathrm{ABO}$-incompatible transplantations. Median ICU-stay after LT was 10 days (range 1-97). Two patients were treated for biopsy-proven rejection. Two patients were diagnosed with vascular complications (one with hepatic artery stenosis and one with portal vein thrombosis), and four patients had biliary complications (two patients with leakage from the cystic duct and two with leakage from the hepaticojejunostomy). Eleven patients were in need of temporary renal replacement therapy after transplantation. Median follow-up time was 70.5 months (range 2.2-171).

Survival time was calculated from the day of LT until December 31, 2017, or to patient death. For the patients that were re-transplanted due to PNF, the calculation is based on the last liver graft. Five and ten-year KaplanMeier (KM) estimateted survival for the whole cohort was $64.8 \%$ and $51.9 \%$, respectively. The five and ten-year KM estimated sur-vival for the patients were both $80.0 \%$, whereas the corre-sponding results for the patients with malignant disease was $57.1 \%$ and $38.1 \%$, respectively (Fig. 1a, b). Table 2 provides further details on MELD score, perioperative morbidity, waiting time, donor-data, and main postoperative complica-tions. Table 3 presents details on the four patients transplanted due to CRLM.

\section{Discussion}

In this report, we present our experience with salvage LT for iatrogenic vascular injuries and for complications to cancer surgery beyond conventional criteria. The study shows that LT is a lifesaving procedure for patients with devastating iatrogenic injuries to the portal vein and hepatic artery and for patients experiencing posthepatectomy liver failure. Longterm survival was achieved for the majority of the patients. However, more than half of the patients with malignant disease died of cancer recurrence.

Salvage LT in case of iatrogenic injuries or posthepatectomy liver failure poses not only medical considerations, but also ethical concerns in the face of organ shortage [20-24]. The availability of organs for transplantation is a crucial limi-tation, which directs the prioritization at each center and complicates the establishment of generally accepted indi-cations, criteria for acceptance, and allocation policies. ALF caused by iatrogenic injuries is a less controversial indication for LT compared to salvage LT for surgical com-plications after treatment for malignancies beyond the con-ventional criteria for transplantation. Our study demon-strates that it is difficult to predict the outcome in both circumstances. The cohort includes a heterogeneous group of patients in terms of primary diagnosis, operative proce-dures, mechanism of liver failure and the general clinical status. This is partly in line with the experiences with LT for ALF within conventional criteria such as toxic liver failure, acute viral hepatitis, and idiopathic acute and subacute liver failure $[25,26]$. However, for these conditions, 
Table 1 Patient characteristics, indications for liver transplantation, and main outcome

\begin{tabular}{|c|c|c|c|c|c|c|c|c|c|c|}
\hline Pat & $\begin{array}{l}\text { Age/ } \\
\operatorname{sex}\end{array}$ & Disease & Primary procedure & $\begin{array}{l}\text { Primary } \\
\text { procedure } \\
\text { performed } \\
\text { at OUS }\end{array}$ & Cancer & Reason for $\mathrm{LT}$ & $\begin{array}{l}\text { Time from } \\
\text { primary } \\
\text { procedure } \\
\text { to LT (days) }\end{array}$ & $\begin{array}{l}\text { Follow-up } \\
\text { (months) }\end{array}$ & Alive & Outcome \\
\hline 1 & $46 / M$ & Gallstones. HCV & Laparoscopic cholecystectectomy & No & No & Iatrogenic injury to PV and $\mathrm{HA}$ & 2 & 121 & Yes & Recurrence of $\mathrm{HCV}$, otherwise well \\
\hline 2 & $22 / \mathrm{M}$ & $\begin{array}{l}\text { Knife stab injury } \\
\text { to abdomen }\end{array}$ & Abdominal packing for hemorrhage & No & No & $\begin{array}{l}\text { Liver failure after hypovolemia } \\
\text { and abdominal packing }\end{array}$ & 4 & 71 & Yes & Recovered \\
\hline 3 & $42 / \mathrm{F}$ & $\begin{array}{l}\text { Suspected renal } \\
\text { carcinoma (benign) }\end{array}$ & Laparoscopic nephrectomy & No & No & Iatrogenic injury to PV and $\mathrm{HA}$ & 17 & 97 & Yes & $\begin{array}{l}\text { Recovered. Stented HAS. Repeated } \\
\text { episodes of cholangitis due to } \\
\text { stenotic biliary tracts in segment } \\
5 / 8, \text { successfully treated with } \\
\text { partial PV embolization }\end{array}$ \\
\hline 4 & $62 / M$ & $\begin{array}{l}\text { Suspected duodenal } \\
\text { cancer (high grade } \\
\text { dysplasia) }\end{array}$ & Pancreatoduodenectomy & Yes & No & $\begin{array}{l}\text { Liver failure after occlusion of } \\
\text { stented HA-pseudoaneurysm }\end{array}$ & 37 & 7 & No & Death due to pneumonia and sepsis \\
\hline 5 & $63 / \mathrm{M}$ & $\begin{array}{l}\text { Suspected HCC } \\
\text { (regeneration } \\
\text { nodules) }\end{array}$ & Right hepatectomy & Yes & No & Remnant liver failure & 27 & 13 & Yes & Recovered \\
\hline 6 & $52 / \mathrm{M}$ & $\begin{array}{l}\text { Suspected CCA } \\
\text { (benign IgG4 } \\
\text { inflammation) }\end{array}$ & Right hepatectomy & Yes & No & Remnant liver failure & 17 & 2 & Yes & Recovered \\
\hline 7 & $49 / \mathrm{M}$ & $\begin{array}{l}\mathrm{HCC} 2,1 \mathrm{~cm} / \text { Child A } \\
\text { cirrhosis }\end{array}$ & Local liver resection & No & Yes & Remnant liver failure & 22 & 110 & Yes & No signs of recurrence, doing well \\
\hline 8 & $69 / \mathrm{M}$ & CRLM & Right hepatectomy & Yes & Yes & $\begin{array}{l}\text { Remnant liver failure } \\
\text { (PV thrombosis) }\end{array}$ & 9 & 78 & No & Death due to recurrence of cancer \\
\hline 9 & $69 / \mathrm{M}$ & CRLM & Right hepatectomy & No & Yes & Remnant liver failure & 20 & 72 & Yes & Recovered, no signs of recurrence \\
\hline 10 & $67 / M$ & CRLM & Planned right hepatectomy & Yes & Yes & $\begin{array}{l}\text { Iatrogenic injury to left branches } \\
\text { of PV and HA }\end{array}$ & 6 & 45 & No & Death due to recurrence of cancer \\
\hline 11 & $63 / \mathrm{M}$ & CRLM & $\begin{array}{l}\text { Resection and auto-transplantation } \\
\text { liver }\end{array}$ & Yes & Yes & $\begin{array}{l}\text { Remnant liver failure due to } \\
\text { intraoperatively massive } \\
\text { bleeding }\end{array}$ & 0 & 9 & No & Death due to recurrence of cancer \\
\hline 12 & $42 / \mathrm{M}$ & PNET /liver metastasis & Planned distal pancreatic resection & Yes & Yes & Iatrogenic injury to PV and $\mathrm{HA}$ & 1 & 177 & Yes & Recovered, no signs of recurrence \\
\hline 13 & $55 / \mathrm{M}$ & Duodenal cancer & Pancreatoduodenectomy & Yes & Yes & $\begin{array}{l}\text { Liver failure after } \\
\text { HA-pseudoaneurysm } \\
\text { and HAT }\end{array}$ & 22 & 24 & No & Death due to recurrence of cancer \\
\hline
\end{tabular}

OUS, Oslo University Hospital; LT, liver transplantation; PNET, pancreatic neuroendocrine tumor; PV, portal vein; HA, hepatic artery; HCV, hepatits C virus; HCC, hepatocellular carcinoma; HAS, hepatic artery stenosis; CRLM, colorectal liver metastasis; HAT, hepatic artery thrombosis 
Table 2 Details on patients, procedures, and results

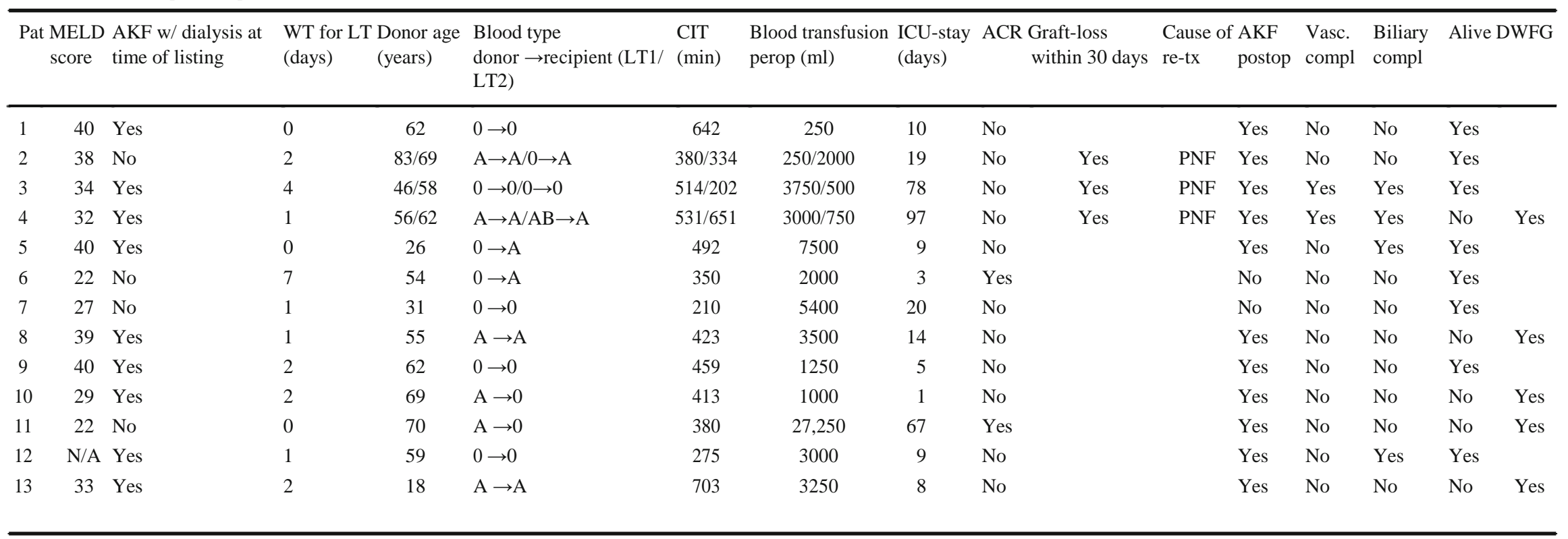

- MELD, model for end-stage liver disease; AKF, acute kidney failure; WT, waiting time; LT, liver transplantation; CIT, cold ischemia time; ICU, intensive care unit; ACR, acute cellular rejection; Re-tx, retransplantation; DWFG, dead with functioning graft; N/A, not applicable; PNF, primary non-function 


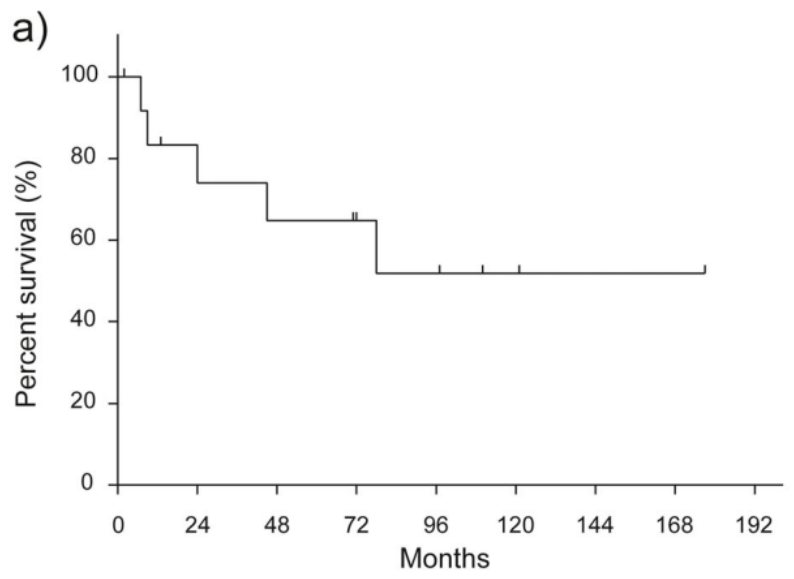

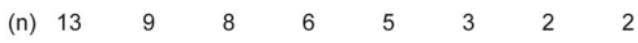

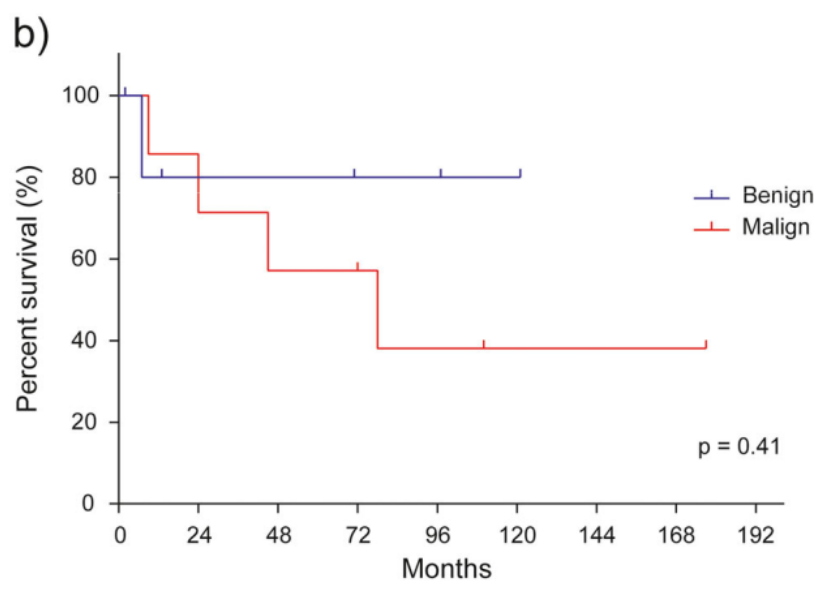

$\begin{array}{lllllll}\text { Benign (n) } & 6 & 4 & 4 & 3 & 3 & 2 \\ \text { Malign (n) } & 7 & 6 & 5 & 4 & 3 & 2\end{array}$

Fig. 1 a Kaplan-Meier plot of patient and graft survival for the whole rescue group. For the three patients that were re-transplanted due to pri-mary non-function, the calculation is based on the last liver graft. b. Kaplan-Meier plots of patient and graft survival in the benign group vs malign group. For the three patients that were retransplanted due to primary non-function, the calculation is based on the last liver graft. Curves were compared using the log-rank test there are well-established recommendations such as the King's college guidelines [27]. For iatrogenic injuries, the reported experiences are scarce [11]. Patient 1 and 2 in our cohort underwent LT after vascular injuries, and the primary procedure was performed due to a non-malignant medical condition. Both patients recovered and, in our view, represent cases that should be offered transplantation whenever possible. Thus, these groups are now included in the conventional ALF-group considered for LT in our center. Iatrogenic injuries that occur during surgery for cancer or suspected malignant disease are more challenging. Patient 3 and 4 underwent surgery for suspected renal and duodenal cancer, respectively. However, malignancy was excluded by final histology prior to transplantation in patient 4 . The liver failure in this patient was caused by thrombosis in a stent in the hepatic artery placed due to a pseudoaneurysm after a pancreatoduodenectomy. This may be considered as an iatrogenic vascular injury finally indicating LT. Hepaticarterypseudoaneurysm after pancreatoduodenectomy carries a high mortality rate. Radiological intervention with stent placement is the firstline treatment. However, with complex arterial pathologies, as were the case in the two patients in our study, surgical revascularization, or even LT, may be the only lifesaving option to avoid lethal liver failure. To the best of our knowledge, LT has not been reported as a treatment option in this setting. Patient 3 was transplanted at a time when malignant kidney tumor was still suspected, and the benign diagnosis was confirmed after transplantation. This case poses several questions as no definite diagnosis had been made at the time of transplantation. Our decision to offer this patient transplantation was partly based on the dramatic consequences of an iatrogenic injury that occurred during surgery of a potentially curable kidney tumor.

Eight patients in our cohort underwent a liver resection for suspected or verified malignancy and were transplanted due to remnant liver failure. Two of these patients (5 and 6) did not have cancer and one patient (7) had HCC in a cirrhotic liver where the tumor was within established criteria for LT. However, the fourth and the fifth patient $(8,9)$ developed liver remnant failure after right hepatectomy for CRLM. All these five patients (5-9) developed grade C posthepatectomy liver failure according to the classification suggested by the International Study Group of Liver Surgery [28]. The

Table 3 Details on patients undergoing liver transplantation for colorectal liver metastasis

\begin{tabular}{|c|c|c|c|c|c|c|c|c|}
\hline Pat & $\begin{array}{l}\text { Diameter of } \\
\text { largest tumor } \\
(\mathrm{cm})\end{array}$ & $\begin{array}{l}\text { Number } \\
\text { of tumors }\end{array}$ & $\begin{array}{l}\text { Last CEA } \\
\text { before LT } \\
(\mu \mathrm{g} / \mathrm{l})\end{array}$ & $\begin{array}{l}\text { Preop. } \\
\text { chemotherapy } \\
(\mathrm{Y} / \mathrm{N})\end{array}$ & $\begin{array}{l}\text { Response to chemotherapy } \\
\text { according to RECIST (Y/N/SD) }\end{array}$ & $\begin{array}{l}\text { Time from primary } \\
\text { diagnosis to LT (months) }\end{array}$ & $\begin{array}{l}\text { Survival } \\
\text { (months) }\end{array}$ & $\begin{array}{l}\text { Alive } \\
(\mathrm{Y} / \mathrm{N})\end{array}$ \\
\hline 8 & 3.0 & 1 & 3.5 & $\mathrm{Y}$ & $\mathrm{Y}$ & 5.9 & 78 & $\mathrm{~N}$ \\
\hline 9 & 2.3 & 3 & $<1.0$ & $\mathrm{Y}$ & $\mathrm{Y}$ & 11.5 & 72 & $\mathrm{Y}$ \\
\hline 10 & 14.0 & 4 & 189 & $\mathrm{Y}$ & SD & 7.3 & 45 & $\mathrm{~N}$ \\
\hline 11 & 5.5 & 2 & 137 & $\mathrm{Y}$ & SD & 24.5 & 9 & $\mathrm{~N}$ \\
\hline
\end{tabular}

CEA, carcinoembryonic antigen; LT, liver transplantation 
remaining three patients with posthepatectmy liver failure were also transplanted after primary surgery for a malignancy outside established criteria for LT. Due to the study design and small study sample, it is not possible to draw any conclusions regarding LT for patients with malignancy beyond the con-ventional criteria based on this study, except that the patients survive the primary surgical procedure, and do not die of ALF. If salvage LT is considered after surgery for suspected malig-nant disease, a detailed histology report should be available to confirm the diagnosis, and to evaluate the tumor stage and prognosis before a final decision for LT is made. Two of the patients had CRLM (10 and 11), and one had liver metastases from a pancreatic neuroendocrine tumor (12). These indica-tions for LT are certainly controversial in a situation with or-gan shortage, and three of the four patients with CRLM died due to recurrence of cancer. Our institution has explored the potential benefit of transplanting patients with CRLM without extrahepatic disease in the SECA-study with encouraging re-sults [14]. According to the results from the SECA trial, two of these patients could be considered as low risk based on max-imal tumor diameter $<5$ $\mathrm{cm}$, pre LT CEA level below $80 \mu \mathrm{g} / \mathrm{L}$ and objective response on chemotherapy (14). One of these patients died 78 months after transplantation, and the other patient has still not developed recurrence after 72 months fol-low-up. Since transplantation for CRLM is still experimental and definitive selection criteria has not been established, it is difficult to predict the potential outcome in the setting of postresection failure. This study show that some patients may have acceptable or even exceptional results. Prolonged disease-free and overall survival after LT for CRLM have also recently been published in a cohort from some European cen-ters. Importantly, they found that compassionate transplanta-tion as a salvage procedure was associated with poorer out-come with respect to disease-free survival than patients where LT was a planned procedure [29]. To further conclude regarding the outcome of $\mathrm{LT}$ for patients with malignancy beyond the conventional criteria, further studies with larger sample size are needed.

Patient survival in some of the previous reports on the use of urgent LT has not been encouraging, with short-term mortality up to $80 \%$ [7, 11]. Table 4 summarizes selected earlier reports on acute rescue LT. These results may partly be related to that the patients were in a dismal state at the time of transplantation such as suffering from infections, sepsis or multiorgan failure. These factors are predictors of poor survival in any candidate undergoing LT regardless of the underlying disease.

Certain limitations of this study must be acknowledged. First, this was a retrospective analysis of patients treated at a single institution with all the inherent biases associated with this study design. However, the clinical database used was prospectively maintained and provided complete follow-up data. Second, the sample size was small. However, despite the limitations of the small sample size, this is one of the largest series to date evaluating the outcome of salvage LT for posthepatectomy liver failure and iatrogenic injuries to vital structures of the liver. Last, and most important, the pa-tients were highly selected and underwent LT without a study protocol and predefined criteria. As previously discussed, a fortunate donor situation and short waiting times has enabled LT to patients beyond conventional criteria. Thus, in case of organ shortage or other systems for allocation of available donor organs, the external validity of the study should be considered with caution.

In conclusion, LT can be a lifesaving procedure for patients suffering from iatrogenic liver injuries or posthepatectomy liver failure. LT for liver failure due to portal vein and hepatic artery injuries in patients with non-malignant disease seems justified. However, it is debatable whether patients with known malignant disease beyond accepted LT-criteria should be offered LT in a situation with organ scarcity.

Table 4 Selected studies on acute rescue liver transplantation

\begin{tabular}{|c|c|c|c|}
\hline Author, year & No. pat. with acute LT* & Reason for performing $\mathrm{LT}$ & Outcome \\
\hline Nordin et al., 2001 [1] & 1 & Transection of hilum during OC & Alive after 2 years follow-up \\
\hline Fernandez et al., 2004 [3] & 1 & Ligation of PV and HA during LC & Death after 35 days \\
\hline Zaydfudim et al., 2009 [4] & 2 & $\begin{array}{l}\text { Transection of hilum during 1) open right } \\
\text { adrenalectomy and 2) LC }\end{array}$ & Alive after 2 and 6 years follow-up \\
\hline Parilla et al., 2013 [7] & 5 & Severe injury to hilum with BVI during LC & 4 of 5 patients died within 30 days after LT \\
\hline Leale et al., 2016 [8] & 2 & $\begin{array}{l}\text { 1) Acute-on-chronic liver failure after OC } \\
\text { (Child C) 2) Massive liver-bleeding during LC }\end{array}$ & Alive after 2 and 8 years follow-up \\
\hline Huerta et al., 2006 [9] & 3 & Severe injury to PV during bariatric surgery & Death after few days, 6 weeks and 8 weeks \\
\hline Benedetto et al., 2010 [10] & 2 & Bleeding complications after TIPS & Long-term survival \\
\hline Lauterio et al., 2017 [11] & 2 & $\begin{array}{l}\text { 1) Massive bleeding during liver resection 2) } \\
\text { ALF after HA embolization due to bleeding }\end{array}$ & Long-term survival \\
\hline Tessier et al., 2009 [12] & 1 & Transection of hilum during lap. adrenalectomy & Long-term survival \\
\hline
\end{tabular}

LT, liver transplantation; * defined as LT within 6 weeks after time of primary surgery; OC, open cholecystectomy; PV, portal vein; HA, hepatic artery; LC, laparoscopic cholecystectomy; BVI, bilio-vascular injury; TIPS, transjugular intrahepatic portosystemic shunt 
Authors' contributions T.T: Study conception and design, acqusition of data, analysis and interpretetation of data and drafting of manuscript. J.M.S.: Acqusition of data and drafting of manuscript. K.J.L: Study conception and design, and critical revision of manuscript. P-D.L: Study conception and design, and critical revision of manuscript. E.M.AA: Study conception and design, analysis and interpretetation of data and drafting of manuscript. All authors have approved the final article.

\section{Compliance with ethical standards}

Disclosure The authors of this manuscript have no conflicts of interest to disclose.

Ethical standards The study was approved by the institutional review board according to the general guidelines provided by the regional ethics committee (2015/1442). For this type of study formal consent is not required (retrospective study).

Ethical approval All procedures performed in studies involving human participants were in accordance with the ethical standards of the institutional and/or national research committee and with the 1964 Helsinki declaration and its later amendments or comparable ethical standards.

\section{References}

1. Nordin A, Makisalo $\mathrm{H}$, Isoniemi $\mathrm{H}$, Halme $\mathrm{L}$, Lindgren $\mathrm{L}$, Hockerstedt K (2001) Iatrogenic lesion at cholecystectomy resulting in liver transplantation. Transplant Proc 33(4):2499-2500

2. Buell JF, Cronin DC, Funaki B, Koffron A, Yoshida A, Lo A, Leef J, Millis JM (2002) Devastating and fatal complications associated with combined vascular and bile duct injuries during cholecystec-tomy. Arch Surg (Chicago, Ill : 1960) 137(6):703708 discussion 708-710

3. Fernandez JA, Robles R, Marin C, Sanchez-Bueno F, Ramirez P, Parrilla P (2004) Laparoscopic iatrogeny of the hepatic hilum as an indication for liver transplantation. Liver Transplantation: Official Publication of the American Association for the Study of Liver Diseases and the International Liver Transplantation Society. Liver Transpl 10(1):147-152. https://doi.org/10.1002/lt.20021

4. Zaydfudim V, Wright JK, Pinson CW (2009) Liver transplantation for iatrogenic porta hepatitis transection. Am Surg 75(4):313-316

5. Ardiles V, McCormack L, Quinonez E, Goldaracena N, Mattera J, Pekolj J, Ciardullo M, de Santibanes E (2011) Experience using liver transplantation for the treatment of severe bile duct injuries over 20 years in Argentina: results from a National Survey. HPB: Off J Int Hepato Pancreato Biliary Assoc 13(8):544-550. https:// doi.org/10.1111/j.1477-2574.2011.00322.x

6. Wang Z, Yu L, Wang W, Xia J, Li D, Lu Y, Wang B (2013) Therapeutic strategies of iatrogenic portal vein injury after chole-cystectomy. J Surg Res 185(2):934-939. https://doi.org/10.1016/j. jss.2013.06.032

7. Parrilla P, Robles R, Varo E, Jimenez C, Sanchez-Cabus S, Pareja E (2014) Liver transplantation for bile duct injury after open and laparoscopic cholecystectomy. Br J Surg 101(2):6368. https:// doi.org/10.1002/bjs.9349

8. Leale I, Moraglia E, Bottino G, Rachef M, Dova L, Cariati A, De Negri A, Diviacco P, Andorno E (2016) Role of liver transplanta-tion in bilio-vascular liver injury after cholecystectomy. Transplant Proc 48(2):370-376. https://doi.org/10.1016/j.transproceed.2015. 12.035
9. Huerta S, Li Z, Livingston EH (2006) Outcome of portal injuries following bariatric operations. Obes Surg 16(1):105109. https:// doi.org/10.1381/096089206775222203

10. Di Benedetto F, Mimmo A, D'Amico G, De Ruvo N, Cautero N, Montalti R, Guerrini GP, Ballarin R, Spaggiari M, Tarantino G, Serra V, Pecchi A, De Santis M, Gerunda GE (2010) Liver trans-plantation due to iatrogenic injuries: two case reports. Transplant Proc 42(4):1375-1377. https://doi.org/10.1016/j.transproceed. 2010.03.077

11. Lauterio A, De Carlis R, Di Sandro S, Ferla F, Buscemi V, De Carlis L (2017) Liver transplantation in the treatment of severe iatrogenic liver injuries. World J Hepatol 9(24):1022-1029. https://doi.org/10. 4254/wjh.v9.i24.1022

12. Tessier DJ, Iglesias R, Chapman WC, Kercher K, Matthews BD, Gorden DL, Brunt LM (2009) Previously unreported highgrade complications of adrenalectomy. Surg Endosc 23(1):97102. https://doi.org/10.1007/s00464-008-9947-3

13. Aseni P, Lauterio A, Slim AO, Giacomoni A, Lamperti L, De Carlis L (2010) Life-saving super-urgent liver transplantation with re-placement of retrohepatic vena cava by dacron graft. HPB Surg: World J Hepatic, Pancreatic Biliary Surg 2010:1-4. https://doi.org/ 10.1155/2010/828326

14. Hagness M, Foss A, Line PD, Scholz T, Jorgensen PF, Fosby B, Boberg KM, Mathisen O, Gladhaug IP, Egge TS, Solberg S, Hausken J, Dueland S (2013) Liver transplantation for nonresectable liver metastases from colorectal cancer. Ann Surg 257(5):800-806. https://doi.org/10.1097/SLA.0b013e3182823957

15. Hagness M, Foss A, Egge TS, Dueland S (2014) Patterns of recur-rence after liver transplantation for nonresectable liver metastases from colorectal cancer. Ann Surg Oncol 21(4):1323-1329. https:// doi.org/10.1245/s10434-013-3449-9

16. Dueland S, Hagness M, Line PD, Guren TK, Tveit KM, Foss A (2015) Is liver transplantation an option in colorectal cancer patients with nonresectable liver metastases and progression on all lines of standard chemotherapy? Ann Surg Oncol 22(7):2195-2200. https:// doi.org/10.1245/s10434-014-4137-0

17. Line PD, Hagness M, Berstad AE, Foss A, Dueland S (2015) A novel concept for partial liver transplantation in nonresectable co-lorectal liver metastases: the RAPID concept. Ann Surg 262(1):e5-e9. https://doi.org/10.1097/sla.0000000000001165

18. Dueland S, Foss A, Solheim JM, Hagness M, Line PD (2018) Survival following liver transplantation for liver-only colorectal metastases compared with hepatocellular carcinoma. Br J Surg 105(6):736-742. https://doi.org/10.1002/bjs.10769

19. Kamath PS, Wiesner RH, Malinchoc M, Kremers W, Therneau TM, Kosberg CL, D'Amico G, Dickson ER, Kim WR (2001) A model to predict survival in patients with end-stage liver disease. Hepatology (Baltimore, Md) 33(2):464-470. https://doi.org/10. 1053/jhep.2001.22172

20. Biggins SW (2012) Futility and rationing in liver retransplantation: when and how can we say no? J Hepatol 56(6):1404-1411. https:// doi.org/10.1016/j.jhep.2011.11.027

21. Neuberger J, Mulligan D (2015) Liver allocation: can we ever get it right and should we ever get it right? Hepatology (Baltimore, Md) 61(1):28-31. https://doi.org/10.1002/hep.27359

22. Schaefer B, Zoller H, Schneeberger S (2018) Con: liver transplantation for expanded criteria malignant diseases. Liver Transpl: Off Publ Am Assoc Stud Liver Dis Int Liver Transpl Soc 24(1):104- 111. https://doi.org/10.1002/lt.24975

23. Zarrinpar A, Busuttil RW (2013) Liver transplantation: past, present and future. Nat Rev Gastroenterol Hepatol 10(7):434440. https:// doi.org/10.1038/nrgastro.2013.88

24. Roberts JP (2015) Transplantation: allocation of liver transplants-a road to consensus. Nat Rev Gastroenterol Hepatol 12(11):615-616. https://doi.org/10.1038/nrgastro.2015.181 
25. Stravitz RT, Kramer DJ (2009) Management of acute liver failure. Nat Rev Gastroenterol Hepatol 6(9):542-553. https://doi.org/10. 1038/nrgastro.2009.127

26. Bunchorntavakul C, Reddy KR (2017) Acute liver failure. Clin Liver Dis 21(4):769-792. https://doi.org/10.1016/j.cld.2017.06. 002

27. McPhail MJ, Farne H, Senvar N, Wendon JA, Bernal W (2016) Ability of King's College Criteria and model for end-stage liver disease scores to predict mortality of patients with acute liver failure: a meta-analysis. Clinical Gastroenterology and Hepatology: the OfficialClinicalPractice Journalofthe A $\mathrm{m}$ e r i c a n Gastroenterological Association. Clin Gastroenterol Hepatol 14(4):516-525.e515; quiz e543-e545. https://doi.org/10.1016/j. cgh.2015.10.007

28. Rahbari NN, Garden OJ, Padbury R, Brooke-Smith M, Crawford M, Adam R, Koch M, Makuuchi M, Dematteo RP, Christophi C,
Banting S, Usatoff V, Nagino M, Maddern G, Hugh TJ, Vauthey JN, Greig P, Rees M, Yokoyama Y, Fan ST, Nimura Y, Figueras J, Capussotti L, Buchler MW, Weitz J (2011) Posthepatectomy liver failure: a definition and grading by the International Study Group of Liver Surgery (ISGLS). Surgery 149(5):713-724. https://doi.org/ 10.1016/j.surg.2010.10.001

29. Toso C, Pinto Marques H, Andres A, Castro Sousa F, Adam R, Kalil A, Clavien PA, Furtado E, Barroso E, Bismuth H (2017) Liver transplantation for colorectal liver metastasis: survival with-out recurrence can be achieved. Liver Transpl: Off Publ Am Assoc Stud Liver Dis Int Liver Transpl Soc 23(8):10731076. https://doi. org/10.1002/lt.24791

Publisher's note Springer Nature remains neutral with regard to juris-dictional claims in published maps and institutional affiliations. 